\title{
Cuff inflation as an aid to nasotracheal intubation using the Airtraq ${ }^{\circledR}$ laryngoscope
}

\author{
Fu S. Xue, MD · Jian H. Liu, MD • Yu J. Yuan, MD • \\ Xu Liao, MD · Qiang Wang, MD
}

Received: 4 January 2010/ Accepted: 3 February 2010/Published online: 12 February 2010

(C) Canadian Anesthesiologists' Society 2010

\section{To the Editor,}

The Airtraq ${ }^{\circledR}$ laryngoscope (Prodol Meditec S.A., Biscay, Spain) is a new disposable optical laryngoscope with the ability to provide a full view of the glottis without the necessity to align oral, pharyngeal, and laryngeal axes. This device has been used successfully for orotracheal and nasotracheal intubation (NTI) in an uncomplicated or difficult airway. ${ }^{1-4}$ Also, a mannequin study suggests that the Airtraq $^{\circledR}$ laryngoscope offers potential advantages over standard direct laryngoscopy for NTI. ${ }^{5}$ However, when NTI is performed with the Airtraq ${ }^{\circledR}$ laryngoscope, we find that difficulty in directing the tube tip into the visualized glottis is a common problem. Here, we report our experience using a cuff inflation technique to address this issue.

After local ethics committee approval and written informed consent, we recruited 72 patients ( 29 males and 43 females) into the study. The patients, ASA physical status I-II and aged 18 to $51 \mathrm{yr}$, were scheduled for elective oral and maxillofacial surgery under general anesthesia with NTI to optimize the surgical approach. Exclusion criteria included patients with a known or predicted difficult airway and those with a history of severe nasal trauma and recurrent epistaxis. In this study, we used the Portex ${ }^{\circledR}$

Fu S. Xue and Jian H. Liu are contributed equally to this work.

All authors state that the Airtraq ${ }^{\circledR}$ laryngoscopes used in this manuscript are purchased retail from manufacturers, and no author has any financial support or potential conflicts of interest for this work.

F. S. Xue, MD $(\varangle) \cdot$ J. H. Liu, MD · Y. J. Yuan, MD .

X. Liao, MD - Q. Wang, MD

Plastic Surgery Hospital, Chinese Academy of Medical Sciences and Peking Union Medical College, Beijing,

People's Republic of China

e-mail: fruitxue@yahoo.com.cn polar preformed cuffed nasotracheal tubes with inner diameters of 7.0 and $6.5 \mathrm{~mm}$ (Portex, Keene, NH, USA) for male and female patients, respectively. Prior to NTI, the patients' nasal passages were prepared with vasoconstrictor and water-soluble jelly. All tracheal intubations were performed by an anesthesiologist (F.S.X.) who had been trained on the use of an Airtraq ${ }^{\circledR}$ laryngoscope in a shortterm airway management program and who had performed the NTI using this device in more than 20 patients prior to this study.

After anesthesia induction and establishing mask ventilation, a nasotracheal tube was inserted via the preselected nostril until the tube tip passed through the posterior naris. Next, an orotracheal Airtraq ${ }^{\circledR}$ laryngoscope was passed into the patient's mouth over the tongue in the midline. After the distal end of the Airtraq ${ }^{\circledR}$ laryngoscope was positioned in the vallecula with the glottis in the centre of the viewfinder, the nasotracheal tube tip was advanced and guided toward the glottis. If the tube tip failed to be aligned with the glottis, the tube was withdrawn until the cuff was below the distal end of the Airtraq ${ }^{\circledR}$ laryngoscope. At this position, an assistant slowly inflated the cuff with a $20 \mathrm{~mL}$ syringe until the tube tip was aligned with the visualized glottis under direct vision on the viewfinder (Figure 1). Then, the tube was re-advanced an additional 1.0 to $1.5 \mathrm{~cm}$ to pass the glottis. Subsequently, the cuff was deflated and the tube was inserted into the trachea until the cuff was $2 \mathrm{~cm}$ below the glottis.

Nasotracheal intubation was successful in 49 of the 72 patients at the first attempt without cuff inflation. However, in the remaining 23 patients, the nasotracheal tube tip could not be brought into alignment with the glottis during the initial intubation attempt. Sixteen of the 23 incorrect tube tip locations were posterior tip positions and seven were lateral tip positions. By inflating the cuff in these cases, the 


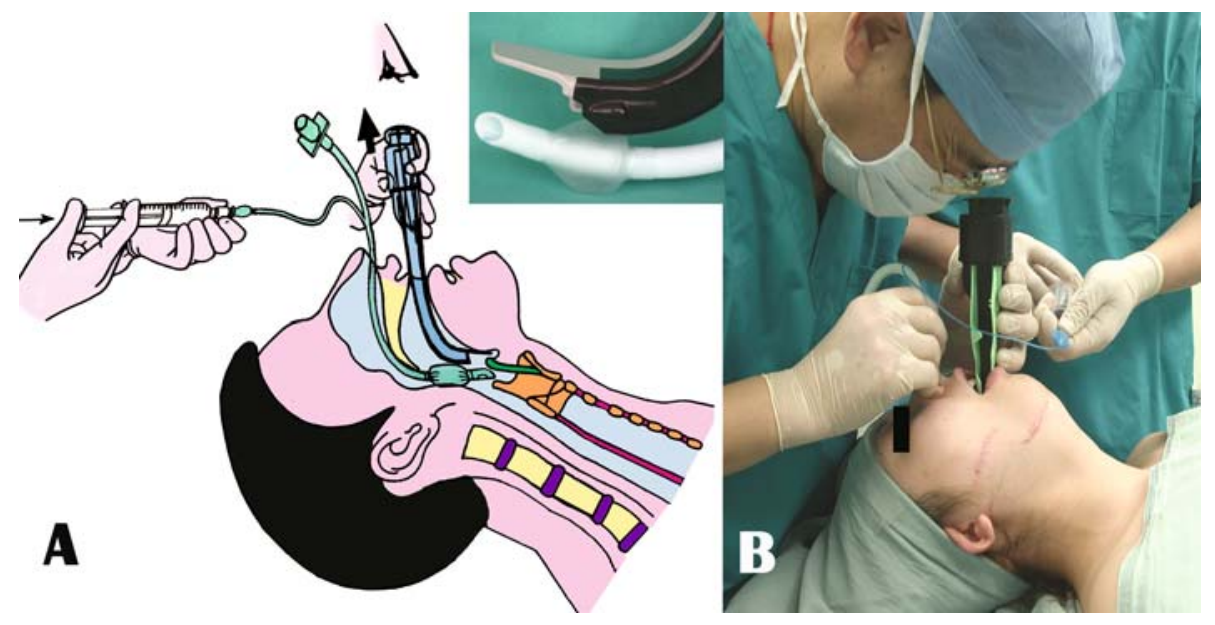

Fig. 1 The cuff inflation technique to overcome the incorrect tube tip location during nasotracheal intubation using the Airtraq ${ }^{\circledR}$ laryngoscope. A The schematic diagram. The inset on the top right hand side shows that the inflated cuff is below the distal end of the Airtraq ${ }^{\circledR}$ laryngoscope and does not interfere with continuous observation of the glottis through the viewfinder. B Clinical procedure of nasotracheal intubation using the Airtraq $^{\circledR}$ laryngoscope

technique may be ineffective in locating the anterior of the nasotracheal tube tip.

Competing interests None declared.

\section{References}

1. Maharaj CH, O'Croinin D, Curley G, Harte BH, Laffey JG. A comparison of tracheal intubation using the Airtraq or the Macintosh laryngoscope in routine airway management: a randomised, controlled clinical trial. Anaesthesia 2006; 61: 1093-9.

2. Savoldelli GL, Ventura F, Waeber JL, Schiffer E. Use of the Airtraq as the primary technique to manage anticipated difficult airway: a report of three cases. J Clin Anesth 2008; 20: 474-7.

3. Asai T. Pentax-AWS videolaryngoscope for awake nasal intubation in patients with unstable necks. Br J Anaesth 2010; 104: 108-11.

4. Hirabayashi $Y$. Nasotracheal intubation with the aid of the Airway Scope. J Clin Anesth 2007; 19: 563.

5. Hirabayashi $Y$, Seo N. Nasotracheal intubation using the Airtraq versus Macintosh laryngoscope: a manikin study. Anesth Prog 2008; 55: 78-81. 